\title{
How Does Internet Finance Influence the Interest Rate? Evidence from Chinese Financial Markets
}

\author{
Changqing Luo ${ }^{1 *}$, Mengzhen Li ${ }^{1}$, Pin Peng ${ }^{1}$, Siyuan Fan ${ }^{1}$ \\ 1 Finance School, Hunan University of Commerce, No.569, Yuelu Avenue, Yuelu District of Changsha, Hunan, P.R.C, \\ 410205 Changsha, CHINA
}

*Corresponding Author: greenro@hotmail.com

Citation: Luo, C., Li, M., Peng, P. and Fan, S. (2018). How Does Internet Finance Influence the Interest Rate? Evidence from Chinese Financial Markets. Dutch Journal of Finance and Management, $2(1), 01$. https://doi.org/10.20897/djfm/89590

Published: April 10, 2018

\begin{abstract}
It is gradually accepted that the Internet finance has increased the accessibility of financial market, and caused an important impact on the financial market. Considering the quick development of the Internet finance in China, we propose theoretical hypotheses to explain the influencing path of Internet finance on market interest rate. Then by using the data from May 2013 to November 2016, we apply UCINET diagram and vector autoregression model and variance decomposition methods to verify the theoretical hypotheses. The empirical results show the Internet finance lead to the change of market interest rate mainly through reference point effect of P2P interest rate. Although the Internet finance affects the social monetization and exchange rate, this impact cannot be passed to interest rate through the medium variables of social monetization and exchange rate.
\end{abstract}

Keywords: Internet finance, interest rate, Chinese financial markets, network relation diagram

\section{INTRODUCTION}

With the acceleration of the reform of interest rate marketization, the People's Bank of China (PBC) gradually relaxed the control of interest rate and established the market-oriented interest rate formation mechanism. In the process of interest rate marketization, Internet finance has gained a broad and sound development environment and shown explosive growth trend in Chinese financial market. According to the data of WIND database, the total amount of Peer-to-Peer (P2P) loan has reached to 219 billion Chinese Yuan. The considerable scale of Internet finance has caused extensive influence on the financial markets and the real economy. Under this background, the government has paid more and more attention to Internet finance.

In July 2015, the PBC and other administrators jointly issued the Guideline on Development of Internet Finance. This guideline encourages the steady development and innovation of Internet finance. Prime Minister Li Keqiang in 2016, also points out that the regulatory authorities should speed up the process of financial reform, perfect the financial supervision mechanism and promote the sustainable development of Internet finance. The 13th FiveYear Plan (2016-2020) officially gives the development potential again. As the result of these support policies, combining with the market need for more convenient financial services, the Internet finance develops quickly and become a vital component of financial markets. Compared to developed financial markets, the innovation ability of traditional financial institutions is restricted by policy and other factors. While the information technology in China develops closely follow the international frontiers, thus, it provides a suitable environment for the boost of the Internet finance, and it also provides a natural experimental environment for us to investigate the Internet finance. 
Since the quick development of the Internet finance, some scholars have studied the Internet finance from different aspects. Xie and Zou (2012) point out that a new finance mode which uses modern information technologies, such as mobile payment, social network, search engine and cloud computation is called Internet finance. Xie et al. (2015) propose some basic theory for the development of the Internet finance. Mild et al. (2015), Serrano-Cinca and Gutierrez-Nieto (2016) and Xia et al. (2017) analyze the risk of P2P lending and design new methods to measure the credit risk. Li and Zhang (2015) study the influence of the third party Internet payment on the velocity of Chinese monetary circulation and verify its role to increase the velocity of money circulation. Liu et al. (2016) support that the Internet finance triggers the fluctuation of narrow money multipliers. Zou and Wang (2017) find the Internet finance has term structure effect on the Chinese commercial banks, and in the short term, the Internet finance will increase the risk of China's banking system, while in the long term, its effect is not obvious.

Judging from the above literature, we can find that it is gradually accepted that the Internet finance has increased the accessibility of the financial market, and caused an important impact on the financial market. The influence of the Internet finance has even penetrated to the fundamental level in the Chinese market and has a significant influence on the money market. To our knowledge, the existing literature has not fully explored the relationship between the Internet finance and market interest rate. To better understand the influence mechanism of the Internet finance, it is essential to investigate the influencing paths of the Internet finance, while most of the existing literature has not paid enough attention to this issue. In our study, we try to answer the question how does Internet finance influence the market interest rate by using the Chinese financial market data, and provide new theoretical and empirical insights for making more reasonable macro-regulation policy and micro-investment and financing decision.

\section{HYPOTHESIS DEVELOPMENT}

To investigate the impact of internet finance on market interest rates, this paper first proposes four primary influencing paths to explain how the Internet finance influence the market interest rate. Then, based on these four paths, we also provide two additional derivative paths to study the influencing mechanism of the Internet finance.

\section{The Influencing Path through Velocity of Money Circulation}

Generally, there is a negative relationship between the velocity of money circulation and interest rate. Li and Tang (2006) explain the mystery of the decline of China's currency circulation rate based on the actual income and interest rate. The empirical analysis shows that there is a negative relationship between currency circulation and interest rate. They insist that with the rise of the money circulation velocity, the actual money supply will increase, thus the interest rate will decrease. Fujiki and Tanaka (2014) argue that the Internet finance, such as the electronic money can enhance the speed of money circulation and reduce the trading cost, thus lead to a lower capital cost and interest rate. With the introducing of the Internet finance, the velocity of money circulation could be enhanced. $\mathrm{Li}$ and Zhang (2015) point out that the Internet finance has the effects of increasing the velocity of monetary circulation. Based on the above analysis, we can provide hypothesis path 1: Internet finance $\rightarrow$ Velocity of money circulation $\rightarrow$ Market interest rate. Specifically, the influencing path is developed as $\left(\mathrm{H}_{1}\right)$ :

$\mathrm{H}_{1}$ : The Internet finance can increase the velocity of money circulation, and a faster the money flow rate can lead to a lower the market interest rate.

\section{The Influencing Path through Degree of Social Monetization}

Monetization often refers to exchanging possessions for cash or cash equivalents. With the development of the Internet finance, the Internet finance may partly substitute the traditional financial organization, and enhance the overall financial supply (Franklin, 2002). Liu et al. (2016) finds that the development of Internet finance increases the sensitivity of bank deposit scale, and improves the effectiveness of the price-based monetary policy. The Internet finance is lack of sufficient supervision, and the monetization could be enhanced. On the other side, the Internet finance may improve social monetization from microeconomic level. For example, Berger insists that the Internet finance can loosen district restriction, and improve the operation efficiency of a financial institution, thus increase the liquidity of the financial market and social monetization. Economides (2001), Delong and Deyoung (2007) and Zou and Wang (2017) also prove this point of view. With a higher social monetization level, the market participant has more access to financial markets, and the average cost of financing is decreased. Thus the overall interest rate will also be decreased. Thus, the second influencing path is provided as Path 2: Internet finance $\rightarrow$ Degree of social monetization $\rightarrow$ Market interest rate. Specifically, the hypothesis $\left(\mathrm{H}_{2}\right)$ is as follow:

$\mathrm{H}_{2}$ : The Internet finance can increase of social monetization level and thus cause the decline in market interest rates. 


\section{The Influencing Path through Foreign Exchange Rate}

There has been considerable literature discussing the relationship between foreign exchange rate and interest rate. Ayuso and Restoy (1996) and Giovanni and Shambaugh (2014) investigate the relationship between interest rate and exchange rate, and they find a significant relationship by using different countries' data. In China, there is also some scholars study this relationship. For example, Wang and Lin (2007) show that there is some other recurrent linkage between RMB nominal exchange rate and interest rate. Liu and Wang (2014) point out that when the exchange rate is situated in the high regime, the decline range of interest rate is greater than that of the low regime. With the introduction of Internet finance, the market participants in the foreign exchange market may benefit from the big data technology, social network, search engine, Cloud computation and other advanced technology. Thus, the ability to receive and process information will be greatly enhanced. In China, the capital account is still in managed condition, the capital of Internet finance can not get access to foreign exchange market convenient, the impact of Internet finance on foreign exchange market can be realized by the externality effect of the Internet finance. Thus, we provide the third influencing path, Path 3: Internet finance $\rightarrow$ Foreign exchange rate $\rightarrow$ Market interest rate. Specifically, the hypothesis $\left(\mathrm{H}_{3}\right)$ is as follow:

$\mathrm{H}_{3}$ : The Internet finance can have an impact on exchange rate and thus lead to the change of market interest rate.

\section{The Influencing Path through Reference Effect}

Kahneman and Tversky (1979), Long and Nasiry (2014), Guo et al. (2016) and some other literature use reference point effect to explain the asset price variation. When making decisions, the investors or other decision makers always find a reference point to compare the relative loss or gain from expectation or aspiration level. For Internet finance in China, although the scale of Internet finance is relatively small when compared to the whole financial market, it forms its interest rate which is mainly the P2P loan rate. P2P refers to the loan interest rates of P2P network platform and the price rate of internet financial market. The P2P rate can change the market anticipation of market participants with its higher rate of return, thus affecting the market interest rate. Additionally, if the P2P rate is high enough, investors compare the difference of interest rate in Internet finance markets and traditional markets, they will withdraw the depositor from the commercial banks, thus the commercial banks have to increase the interest rate to attract the depositors. Based on the above analysis, we provide the fourth influencing path, Path 4: Internet finance $\rightarrow$ P2P loan rate $\rightarrow$ Market interest rate. Specifically, the hypothesis $\left(\mathrm{H}_{4}\right)$ is as follow:

$\mathrm{H}_{4}$ : The Internet finance can have an impact on the P2P rate and thus lead to the change of market interest rate.

\section{The Influencing Path through Combination Effect}

There could be a complicated relationship among Internet finance, the velocity of money circulation, social monetization, exchange rate and $\mathrm{P} 2 \mathrm{P}$ rate. Based on the above analysis, we provide additional derivative influencing paths to explain the influence of Internet finance on market interest rate. Internet financial markets first influence the market of interest rates by affecting the money market. In recent years, various kinds of internet financial innovation in China are emerging, and a variety of internet companies such as Alibaba and Tencent, directly compete with the core business of banks and other financial institutions. As a consequence, the internet finance increases money circulation speed and expands the monetary multiplier by providing new convenient payment tools. Therefore, Internet finance affects the speed of money circulation, then has an impact on social monetization, and finally affects the interest rate. Thus, the first derivative path is set as path 5: Internet finance $\rightarrow$ Velocity of money circulation $\rightarrow$ Degree of social monetization $\rightarrow$ Market interest rate). Specifically, the hypothesis $\left(\mathrm{H}_{5}\right)$ is as follow:

$\mathrm{H}_{5}$ : The Internet finance can have an impact on the velocity of money circulation, then pass this impact to the degree of social monetization, and finally to the change of market interest rate.

Meanwhile, the changes of Internet finance cause the fluctuation of the exchange rate, then affect the shift in credit market, and finally affect the volatility of interest rate. According to the Interest Rate Parity criterion, when the rate of return is higher than the international interest rate level, foreign hot money driven by the income will be poured into China. Since July 21, 2005, China begins to implement a floating exchange rate system. To achieve effective control of exchange rates, the central bank will take into account the market supply and demand, as well as the adjustment of a basket of currencies. Therefore, the change of money supply will lead to the change of credit market, and then affect the fluctuation of interest rate. Also, by the impact that the RMB join the SDR, China has further opened the capital account, which will make short-term international hot money in and out of the Chinese foreign exchange market frequently, and cause the fluctuations of the exchange rate. By considering the above 
Table 1. Variable interpretation

\begin{tabular}{lll}
\hline Variable name & Symbol & Variable interpretation \\
\hline $\begin{array}{l}\text { Internet finance } \\
\begin{array}{l}\text { Velocity of money } \\
\text { circulation }\end{array}\end{array}$ & VOL & The trading volume of Peer-to-Peer network loan in China million) \\
\hline Monetization rate & KVU & (GDP+stock turnover + bond turnover + futures turnover) $/$ M2 \\
\hline Exchange rate & ERT & Average exchange rate: USD to RMB (Yuan) \\
\hline Market interest rate & SBR & SHIBOR (interest rate) $(\%)$ \\
\hline P2P lending rate & P2P & China Peer-to-Peer lending rate $(\%)$ \\
\hline
\end{tabular}

factors, we provide the second derivative path as path 6: Internet finance $\rightarrow$ P2P loan rate $\rightarrow$ Foreign exchange rate $\rightarrow$ Market interest rate. Specifically, the hypothesis $\left(\mathrm{H}_{6}\right)$ is as follow:

$\mathrm{H}_{6}$ : The Internet finance can have an impact on P2P loan rate, then pass this impact to exchange rate, and finally to the change of market interest rate.

\section{RESEARCH DESIGN}

\section{Sample and Variable Selection}

Besides the indirect financing and direct financing, there is a third way to conduct the financial activities, and this kind of economic business is called Internet finance in China. The Internet finance refers to the P2P lending, online funding, third-party payment and other forms. In our study, we mainly focus on one of the significant types of Internet finance: P2P lending. By using data from P2P lending, we investigate the influence of Internet finance on market interest rate. We use the trading volume of the P2P lending to evaluate the development of Internet finance, and variables are displayed in Table 1. The sample period is from May 2013 to November 2016. Considering the data availability, the frequency of Internet finance data and other economic data are all monthly data. The data is collected from WIND database.

Variable VOL refers to the trading volume of China's Peer-to-Peer loan. Peer-to-Peer Network loan relates to the individual's borrowing. Compared with traditional lending, the conventional loan has many procedures, high threshold, limited funds and other shortcomings; Peer-to-Peer directly forms the credit between lenders and borrowers through the Internet technology. The P2P lending has attracted a large number of investors and has become a typical form of Internet finance, so it is appropriate to use the trading volume of P2P lending to represent the overall development of the Internet.

Variable FLO refers to the velocity of money circulation. KVU is the Marshallian K of the credit market, also called the monetization rate or the degree of social monetization which is the ratio of exchange value to a gross domestic product. Foreign exchange is the primary ratio between different currencies, which can be regarded as the value of the money of a country to another country, and the exchange rate is an essential mean for various states to implement the monetary policies. In our study, we choose the exchange rate of USD dollar to CNY to measure the foreign exchange rate. For market interest rate, we use SHIBOR (Shanghai Interbank Offered Rate) as the variable (SBR). SHIBOR is calculated on the technological platform of the National Interbank Funding Center in Shanghai, and it is a market-oriented interest rate which takes the average of all price quotation of member banks in interbank markets.

\section{Empirical Research Methods}

Firstly, we detect the possible relationship between variables. There are many tools for social network analysis, such as specialized social network analysis tools UCINET. UCINET is powerful social network analysis software. It has a large number of network analysis indicators, such as the Center, faction analysis, random two-party relationship model, and also includes standard multivariate statistical analysis tools, such as factor analysis, correspondence analysis, clustering analysis. In UCINET, all data is stored, presented, and described in the form of a matrix.

Secondly, we use the vector auto regression and variance decomposition to further examine the paths which is significant in the UCINET diagram. The vector auto regression model is set as follow:

$$
\left[\begin{array}{c}
Y_{1, t} \\
Y_{2, t} \\
\vdots \\
Y_{n, t}
\end{array}\right]=\varphi_{1}\left[\begin{array}{c}
Y_{1, t-1} \\
Y_{2, t-1} \\
\vdots \\
Y_{n, t-1}
\end{array}\right]+\cdots+\varphi_{p}\left[\begin{array}{c}
Y_{1, t-p} \\
Y_{2, t-p} \\
\vdots \\
Y_{n, t-p}
\end{array}\right]+\left[\begin{array}{c}
\varepsilon_{1} \\
\varepsilon_{2} \\
\vdots \\
\varepsilon_{n}
\end{array}\right], t=1,2, \ldots, T
$$

$Y$ are the endogenous variables, which are the variables in the significant paths, and $\mathrm{n}$ is the number of variables in the significant paths. The maximum value of $n$ equals to 6 . Coefficient $\varphi$ represents the relationship between 
Table 2. Descriptive Statistics

\begin{tabular}{|c|c|c|c|c|c|}
\hline Variable & Mean & S.D & Minimum & Maximum & Median \\
\hline VOL & 15.30 & 1.26 & 12.88 & 17.17 & 15.40 \\
\hline FLO & 0.36 & 0.21 & 0.16 & 1.07 & 0.28 \\
\hline KVU & 7.56 & 0.64 & 6.35 & 8.95 & 7.58 \\
\hline ERT & 6.30 & 0.23 & 6.10 & 6.92 & 6.16 \\
\hline SBR & 3.97 & 1.20 & 2.28 & 7.35 & 3.92 \\
\hline P2P & 15.60 & 5.71 & 8.32 & 27.10 & 14.63 \\
\hline
\end{tabular}

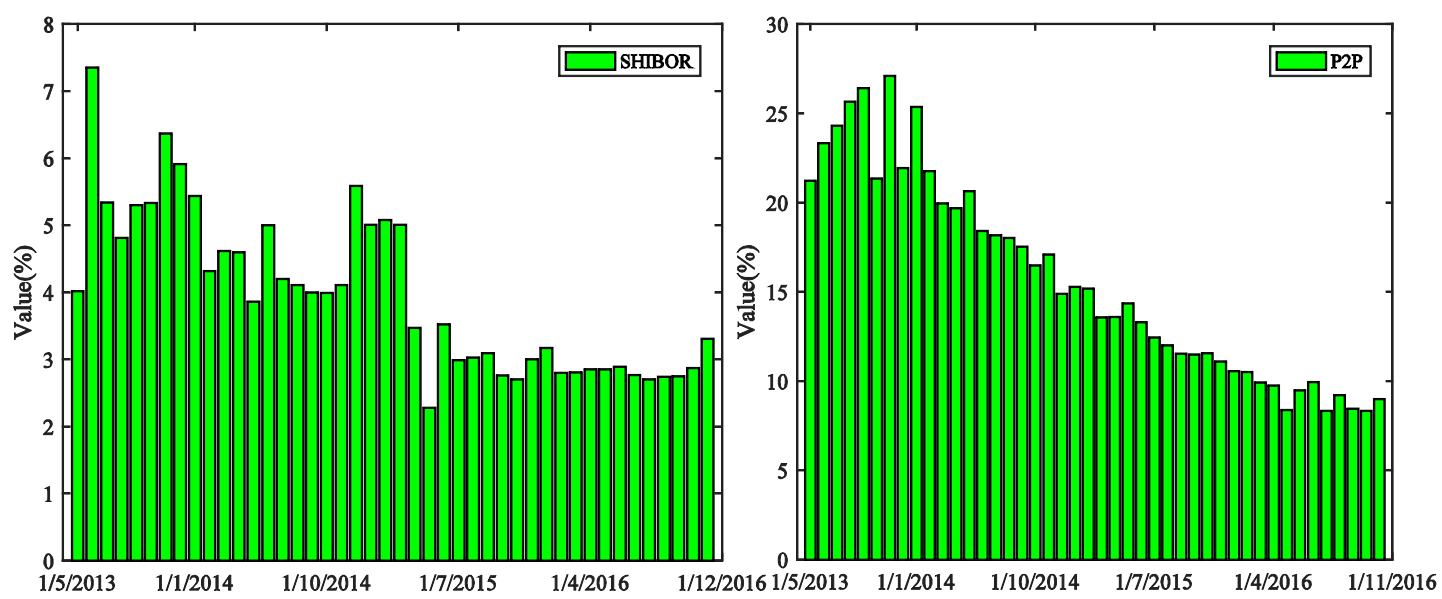

Figure 1. SHIBOR and P2P Interest rate

endogenous potential variables, and $p$ is the lagged order of the vector auto regression models. By estimating the vector auto regression model, we can get the variance of each variable. Thus, the variance contribution of each variable to interest rate can be calculated by the variance decomposition method.

\section{EMPRICAL RESEARCH RESULTS AND ANALYSIS}

\section{Descriptive Statistics and Analysis of Variable}

Considering that the units of each variable are not uniform, the data is not comparable; we use Z-score standardized method to deal with the data in the unit:

$$
N=\frac{X-E(X)}{S D(X)}
$$

where $N$ represents the scaled data, $X$ represents the original data, $E(X)$ represents the mean value of the variable, and $S D(X)$ represents the standard deviation of the variable. The descriptive statistics of variables are displayed in Table 2.

Figure 1 is the market interest rate and Peer-to-Peer net lending rate. There are decreasing over time. Internet finance was emerging in 2013, so most of the new Peer-to-Peer platform provides high returns to attract the investors. With the maturity of the Peer-to-Peer platform, along with the implementation of guidelines and other supervision policies, the interest rate will gradually return to a relatively normal level.

\section{Test Results and Analysis of UCINET Network Relationship}

Figure 2 is a network diagram calculated by using UCINET software, and the network diagram refers to the existence of multiple relationships among different nodes. In the figure above, the closer the shape is, the more closely the variable relates. From the picture above: ERT arrows point to KVU, KVU arrows point to VOL, the three figures are the same size, indicating that three variables are closely linked. Judging by the network relationship, we can find there could be interrelationship among Internet finance and other economic variables.

The position of the SBR and the Peer-to-Peer is closest to the link, and the Peer-to-Peer refers to the interest rate of the Internet finance, while SBR refers to the interest rate level of the banking institution. In 2013, as the Peer-to-Peer platform began to develop, technology and regulation on internet finance were immature. To attract capital, some Internet finance agents provide high interest rate to investors, resulting in a reduction in bank 


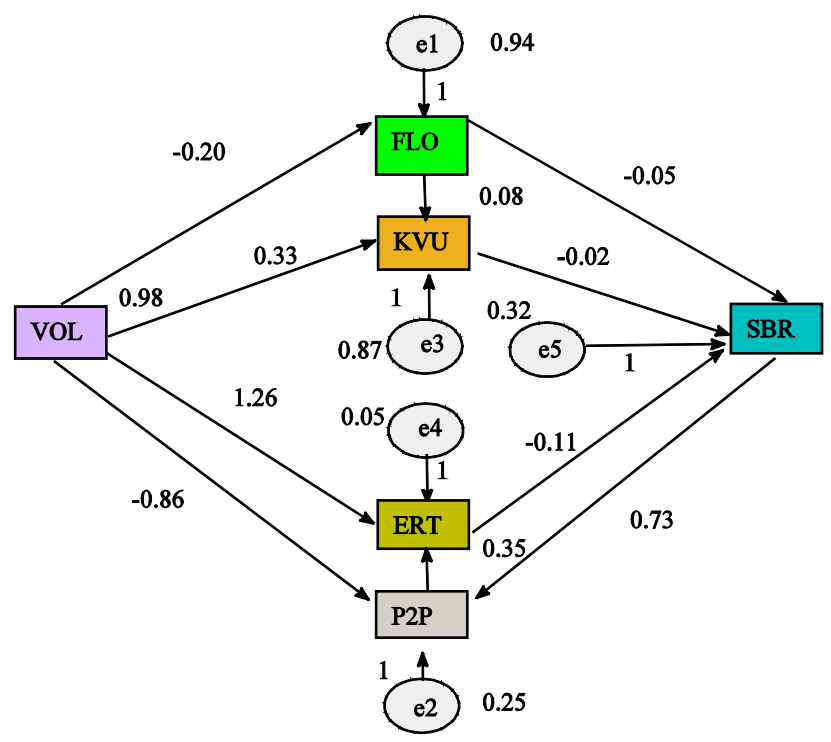

Figure 2. Network diagram of the variables

Table 3. Estimation result of coefficients

\begin{tabular}{ccccc}
\hline Path & Estimate & S.E. & C.R. & P \\
\hline VOL $\rightarrow$ FLO & -0.200 & 0.149 & -1.338 & 0.181 \\
\hline VOL $\rightarrow$ P2P & -0.864 & 0.077 & 11.251 & 0.000 \\
\hline VOL $\rightarrow$ KVU & 0.330 & 0.147 & 2.244 & 0.025 \\
\hline VOL $\rightarrow$ ERT & 1.257 & 0.072 & 17.505 & 0.000 \\
\hline FLO $\rightarrow$ KVU & 0.081 & 0.147 & 0.552 & 0.581 \\
\hline $\mathrm{P} 2 \mathrm{P} \rightarrow$ ERT & 0.349 & 0.072 & 4.857 & 0.000 \\
\hline $\mathrm{FLO} \rightarrow$ SBR & -0.055 & 0.089 & -0.614 & 0.539 \\
\hline $\mathrm{KVU} \rightarrow \mathrm{SBR}$ & -0.015 & 0.092 & -0.166 & 0.868 \\
\hline $\mathrm{ERT} \rightarrow \mathrm{SBR}$ & -0.108 & 0.131 & -0.824 & 0.410 \\
\hline $\mathrm{P} 2 \mathrm{P} \rightarrow \mathrm{SBR}$ & 0.729 & 0.129 & 5.634 & 0.000 \\
\hline
\end{tabular}

deposits. Banks, to prevent the continued loss of deposits, have to raise the level of interest rates, so there is a positive correlation between the two variables. The network diagram also conforms to assumption $4\left(\mathrm{H}_{4}\right)$.

The Coefficients of VOL and FLO is -0.20 , which did not pass the hypothesis test under $5 \%$ significant levels. Thus, Hypothesis $\mathrm{H}_{1}$ is not verified. For the path2, the coefficients between KVU and VOL, and KVU and SBR is respectively 0.330 and -0.015 , and the $p$-value is 0.025 and 0.868 . Thus, the hypothesis $\mathrm{H}_{2}$ is partly verified The Internet finance has an impact on the social monetization, but the social monetization is not the driven factor of market interest rate in Chinese financial market. Similar to the path 2, the path 3 is only partly verified, since the Internet finance have an impact on the exchange rate, while the relationship between market interest rate and the exchange rate is not significant in the sample period. For the path 4, we can find the reference point effect of the Internet finance is significant. The VOL significantly influence the $\mathrm{P} 2 \mathrm{P}$ rate, and the $\mathrm{P} 2 \mathrm{P}$ rate (P2P) is an influencing factor of the market interest rate (SBR). By judging the coefficients, we can also find that the combined effect of the variables is not obvious, and the hypothesis $\mathrm{H}_{5}$ and $\mathrm{H}_{6}$ are not verified.

\section{Test Results of VAR Model and Variance Decomposition}

The UCINET diagram shows that the trading volume significantly changes the P2P interest rate which also has a direct impact on the monetary market interest rate, therefore the path: VOL $\rightarrow \mathrm{P} 2 \mathrm{P} \rightarrow \mathrm{SBR}$ is significant. To further verify this path, we take those three variables into the vector autoregression model to obtain the variance contribution of each variable to the monetary interest rate. The results of the vector autoregression model are listed as follows:

$$
\begin{aligned}
& S B R=0.474 S B R_{t-1}-0.023 S B R_{t-2}+0.151 V O L_{t-1}+1.049 V O L_{t-2}+0.078 P 2 P_{t-1}+0.121 P 2 P_{t-2}-8.98 \\
& V O L=-0.008 S B R_{t-1}-0.024 S B R_{t-2}+0.357 V O L_{t-1}+0.389 V O L_{t-2}-0.015 P 2 P_{t-1}-0.001 P 2 P_{t-2}+2.16 \\
& P 2 P=0.028 S B R_{t-1}+0.404 S B R_{t-2}-3.747 V O L_{t-1}-2.682 V_{O L} L_{t-2}-0.017 P 2 P_{t-1}+0.324 P 2 P_{t-2}+51.28
\end{aligned}
$$


Dutch Journal of Finance and Management, 2(1), 01

Table 4. Variance decomposition of SBR

\begin{tabular}{|c|c|c|c|c|}
\hline Period & S.E. & SBR & VOL & P2P \\
\hline 1 & 0.546 & 100.000 & 0.000 & 0.000 \\
\hline 2 & 0.615 & 97.414 & 0.255 & 2.332 \\
\hline 3 & 0.656 & 89.347 & 0.539 & 10.114 \\
\hline 4 & 0.668 & 87.252 & 0.789 & 11.959 \\
\hline 5 & 0.678 & 85.254 & 1.165 & 13.581 \\
\hline 6 & 0.683 & 84.447 & 1.473 & 14.080 \\
\hline 7 & 0.688 & 83.602 & 1.833 & 14.565 \\
\hline 8 & 0.692 & 83.040 & 2.146 & 14.813 \\
\hline 9 & 0.696 & 82.464 & 2.469 & 15.067 \\
\hline 10 & 0.699 & 81.986 & 2.764 & 15.250 \\
\hline
\end{tabular}

By applying the vector autoregression models, we obtain the variance decomposition results which are shown in Table 4.

Judging from the Table 4, we can find that the variable itself mainly contributes the variation of monetary market interest rate. More than $80 \%$ of SBR variance is from variable SBR. The variance decomposition also verifies the UCINET diagram in section 4.2. Although the internet finance has a relatively weak impact on the monetary market interest rate, the impact is significant. The level of P2P interest rate could be a reference point for the monetary market interest rate. Thus, the variance contribution of the P2P is more than $10 \%$.

To sum up, we can find the Internet finance has a wide impact on the financial markets. As to the market interest rate, the Internet finance plays its role mainly in the indirect path which is called the reference point effect. However, the direct capital flow or path is not the deterministic factors. In China, although the Internet finance, especially the P2P lending develops very quickly, this market is partly segmented from the money market and capital market. Some P2P lending platforms are developed from the industrial companies, and some other P2P companies are even launched by the underground banks. Thus, the Internet finance is partly a circulatory system, but it has a large scale, so the interest rate in this market is reference price for other main financial markets in China.

\section{CONCLUSION AND IMPLICATION}

Considering the quick development of the Internet finance in China, we propose a theoretical hypothesis to explain the influencing paths of Internet finance on market interest rate. By using the data from May 2013 to November 2016, we verify the theoretical hypotheses. The empirical results show that the Internet finance has a significant impact on social monetization, exchange rate, and P2P interest rate, and it will lead to the change of market interest rate through reference point effect of P2P interest rate. Based on the above results, some supervision policies could be adopted for the healthy development of the Internet finance. Firstly, the regulatory authorities should strengthen the supervision on Internet finance. Since the interest rate is a reference point for benchmark market interest rate, the government should keep an eye on the fluctuation on the Internet finance market and reduce the irrational increase of Internet finance interest rate. Secondly, to maintain the stability of the Internet finance market, the authorities can require the Internet platform or related financial institution to set a minimum margin to lower the operational risk of the Internet finance, and thus the interest rate in Internet finance market can be more stable. Thirdly, when implementing the monetary policies, the Internet finance should be taken into account. The central banks should use advanced tools to measure the impact of the Internet finance on the economic activities, thus to implement more effective macro adjustment and control.

\section{ACKNOWLEDGMENT}

This work is supported by the National Natural Science Foundation of China (Grant No. 71503078) and the Hunan Provincial Innovation Foundation for Postgraduate (CX2016B656, CX2017B750).

\section{REFERENCES}

Ayuso, J. and Restoy, F. (1996). Interest rate parity and foreign exchange risk premia in the ERM. Journal of International Money and Finance, 15, 369-382. https://doi.org/10.1016/0261-5606(96)00010-1

Delong, G. and Deyoung, R. (2007). Learning by observing: Information spillovers in the execution and valuation of commercial bank M\&As. Journal of Finance, 62, 181-216. https://doi.org/10.1111/j.1540-6261.2007.01205.x 
Economides, N. (2001). The impact of the internet on financial markets. Journal of Financial Transformation, 1, 8-13.

Franklin, A. (2002). E-finance: an introduction. Journal of Financial Services Research, 22, 5-27. https://doi.org/10.1023/A:1016007126394

Fujiki, H. and Tanaka, M. (2014). Currency demand, new technology and the adoption of electronic money: Evidence using individual household data. Economic Letters, 125, 5-8. https://doi.org/10.1016/j.econlet.2014.07.032

Giovanni, J. and Shambaugh, C. (2014). The impact of foreign interest rates on the economy: The role of the exchange rate regime. Journal of International Economics, 74, 341-361. https://doi.org/10.1016/j.jinteco.2007.09.002

Guo, D., Hu, Y., Wang, S. and Zhao, L. (2016). Comparing risks with reference points: A stochastic dominance approach, 105-116.

Kahneman, D. and Tversky, A. (1979). Prospect theory: An analysis of decision under risk. Econometrica, 47, 263291. https://doi.org/10.2307/1914185

Li, S. J. and Zhang, X. (2015). The influence of the third-party internet payment on the velocity of Chinese monetary circulation. Finance Forum, 20, 25-33.

Li, Z. and Tang, G. (2006). Explanation for the decreasing of velocity circulation in China. The Shanghai Finance, $27,33-34$.

Liu, J. and Wang, D. (2014). RMB exchange rate, asset price and rules of non-linear interest rate. Finance \& Economics, 42, 19-27.

Liu, L., Qi, Y. and Zhang, J. (2016). Impact of internet finance on effectiveness of monetary policy-based on the theoretical framework of microeconomics of banking. Finance and Trade Economics, 37, 61-73.

Long, X. and Nasiry, J. (2014). Prospect theory explains newsvendor behavior: the role of the reference point. Management Science, 61, 3009-3012. https://doi.org/10.1287/mnsc.2014.2050

Mild, A., Waitz, M. and Wuckl, J. (2015). How low can you go? - Overcoming the inability of lenders to set proper interest rates on unsecured peer-to-peer lending markets. Journal of Business Research, 68, 1291-1305. https://doi.org/10.1016/j.jbusres.2014.11.021

Serrano-Cinca, C. and Gutierrez-Nieto, B. (2016). The use of profit scoring as an alternative to credit scoring systems in peer-to-peer (P2P) lending. Decision Support Systems, 89, 113-122. https://doi.org/10.1016/j.dss.2016.06.014

Wang, A. and Lin, N. (2007). Study on the correlation between RMB nominal exchange rate and nominal interest rate. Management Science, 45, 56-67.

Xia, Y. F., Liu, C. and Liu, N. (2017). Cost-sensitive boosted tree for loan evaluation in peer-to-peer lending. Electronic Commerce Research and Applications, 24, 30-49. https://doi.org/10.1016/j.elerap.2017.06.004

Xie, P. and Zou, C. (2012). Research on internet-based finance mode. Journal of Financial Research, 390, 11-22.

Xie, P., Zou, C. and Liu, H. (2015). The fundamental theory of internet finance. Journal of Financial Research, 422, $1-12$.

Zou, J. and Wang, H. (2017). The influence of internet finance on the systematic risk of Chinese commercial banksempirical study based on SVAR model. The Theory and Practice of Finance and Economics, 38, 17-23. 